\title{
SMART TEMPORARY TRAFFIC LightS
}

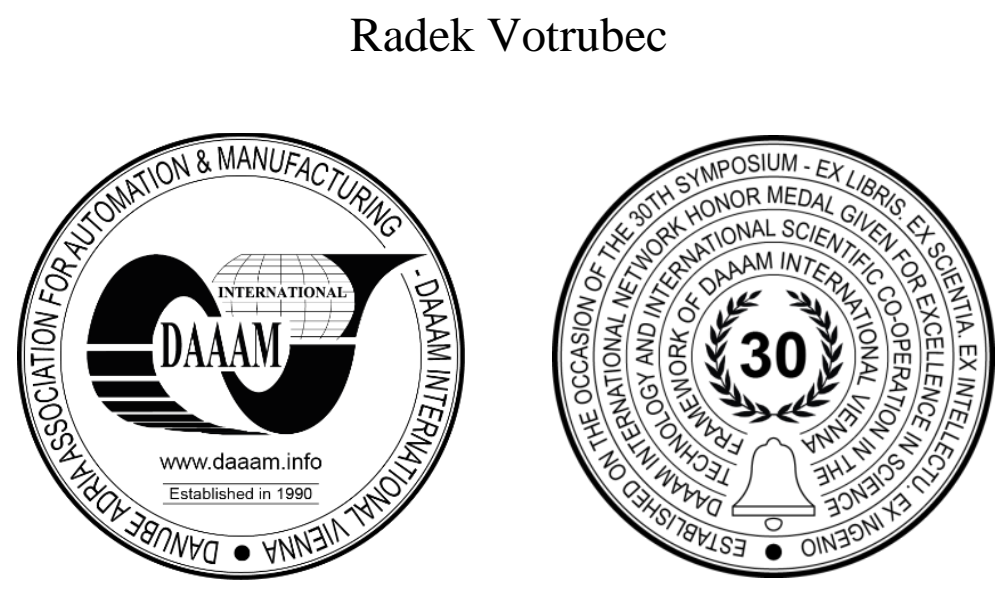

This Publication has to be referred as: Votrubec, R[adek] (2021). Smart Temporary Traffic Lights, Proceedings of the 32nd DAAAM International Symposium, pp.0052-0057, B. Katalinic (Ed.), Published by DAAAM International, ISBN 978-3-902734-33-4, ISSN 1726-9679, Vienna, Austria

DOI: $10.2507 / 32$ nd.daaam.proceedings.008

\begin{abstract}
The aim of this paper is to introduce a control system for a traffic light. In this case, these are not fixed traffic lights at a light-controlled intersection, but temporary traffic signs at an ordinary intersection, for example during road repairs. It is necessary to install four portable traffic lights, two pairs, in this place. These traffic lights cannot be connected with cables. It is therefore proposed to control them using independent microprocessors communicating with each other via wifi. Various control strategies are proposed for this automaton-based system.
\end{abstract}

Keywords: Traffic lights; Microprocessor; Wifi; Arduino; Internet of Things.

\section{Introduction}

At our department we created several production systems or models of production system and home automation systems at in the last years. Production systems and their models are suitable for teaching the modern principles of Industry 4.0. [6], [8], [4], [5]. Manufacturing factories increase in product quality like the main competitive criterion today [9], [7]. All our systems and models consist of elements with their own control systems and communicates with the other elements of the systems via Internet of Things. There are several examples like a model of a smart factory with the production of a colourful bracelet [1], a production system of the little plate with name with milling machine [2] or two models of intelligent houses with smart home automation systems [3]. We have now developed a model of temporary portable traffic lights based on demand from engineering network construction and management companies.

The control system used on the model is suitable for commercial use at real portable traffic lights. In this case, these are not fixed traffic lights at a light-controlled intersection, but temporary traffic signs at an ordinary intersection, for example during road repairs, Fig.1. It is necessary to install four portable traffic lights masts, two pairs, in this place. By default, there are only a few traffic lights for a straight section. These traffic lights do not normally communicate with each other. They cannot be connected using cables because of long distance between them. Their synchronization is based on the use of precise time, which is synchronized by a radio signal from Frankfurt am Main. In our solution, four traffic lights cannot be connected using cables. It was therefore proposed to control them using independent microprocessors communicating with each other via wifi. Various control strategies for this automata-based system are proposed for these traffic lights. 


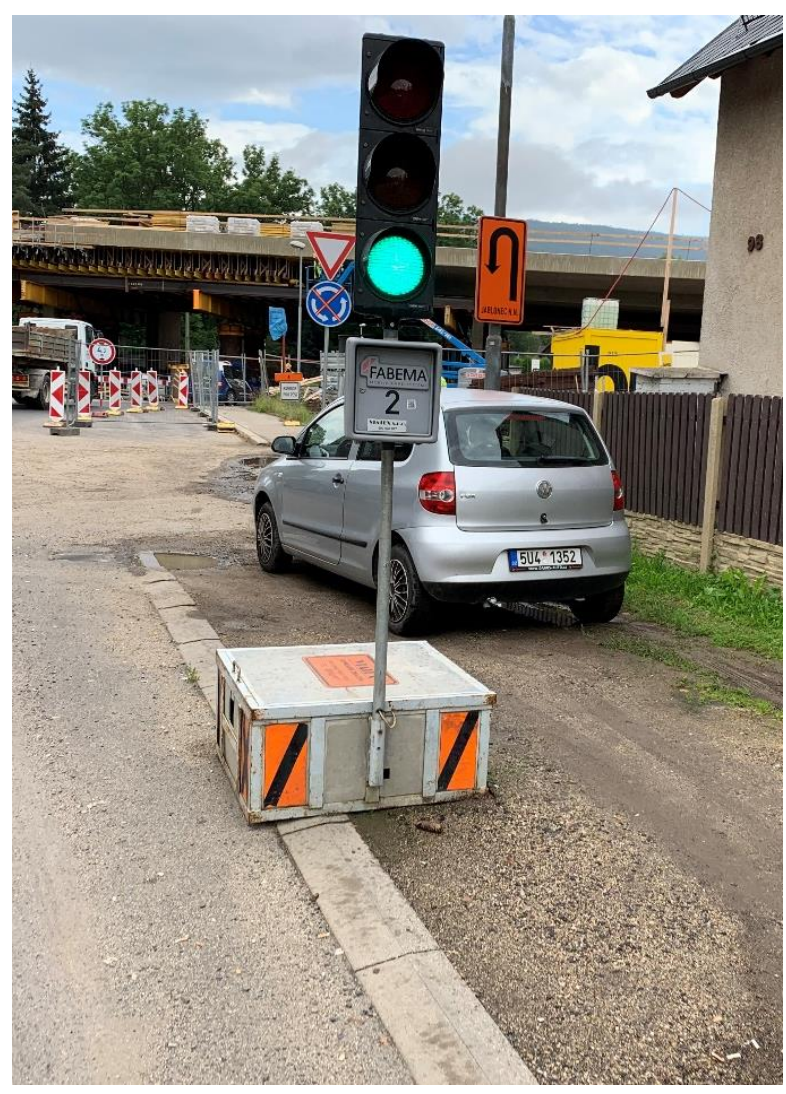

Fig. 1. Portable traffic lights

\section{Control unit for portable traffic lights}

There are several strategies to control the lights and there are two situations. The first is the central control system with one Arduino only, Fig.2. This is an intermediate stage of development. All six colours R1, O1, G1, R2, O2 and G2 are connected with wires to this Arduino.

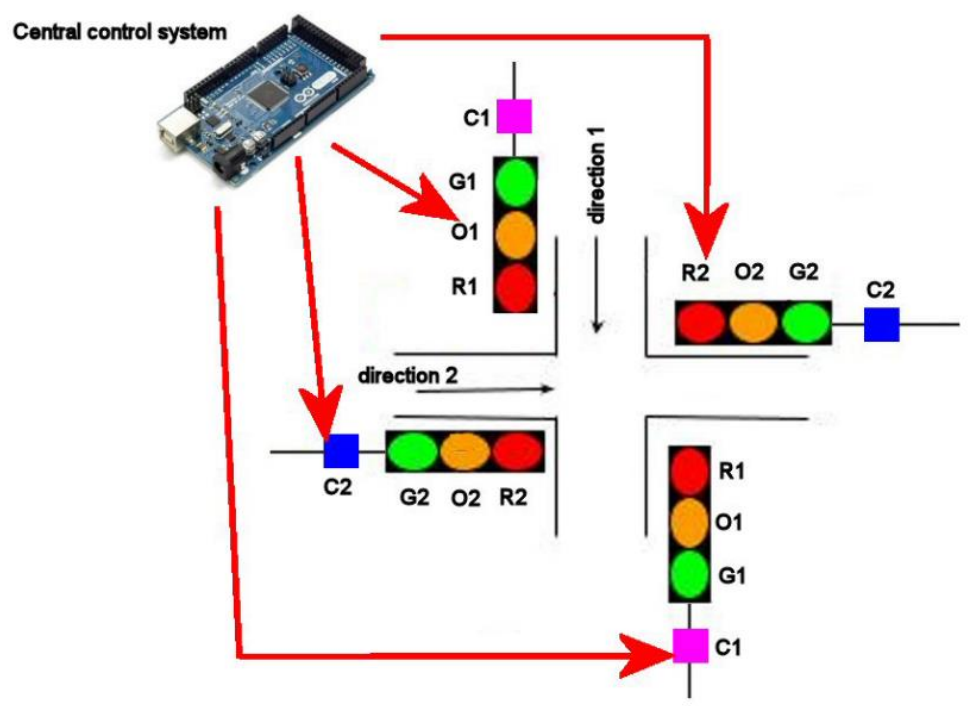

Fig. 2. Central control system

The final solution consists of four alone control systems with four Arduinos, because it is not possible to use wires on the real crossroad. There are four traffic lights masts. First mast is a Master. He does the timing and sends synchronization signal, current state, to other masts. There are two kinds of Slaves. Slave1 is in the same direction like Master and two Slaves2 are in second direction, Fig 3. The photograph of the solution is in Fig.4. 

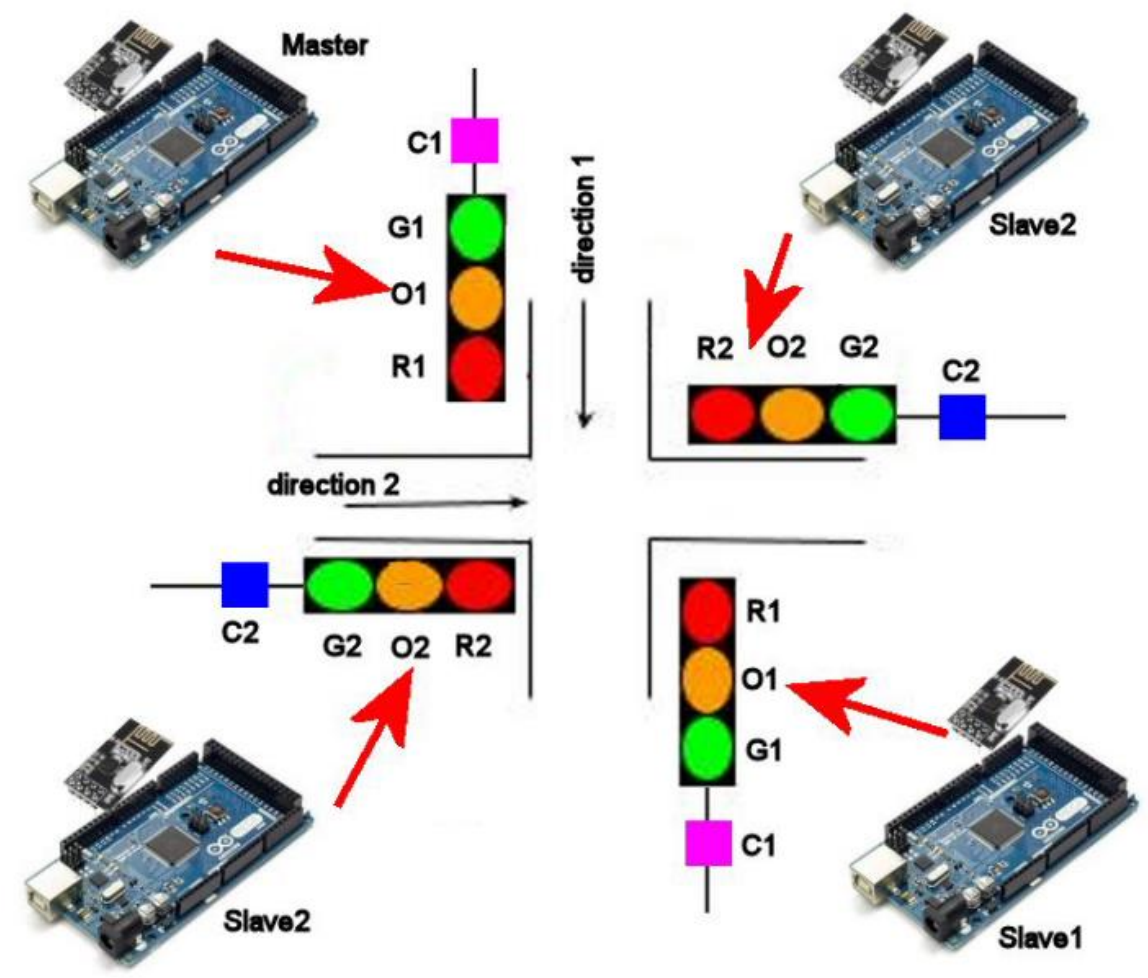

Fig. 3. Independent components IoT

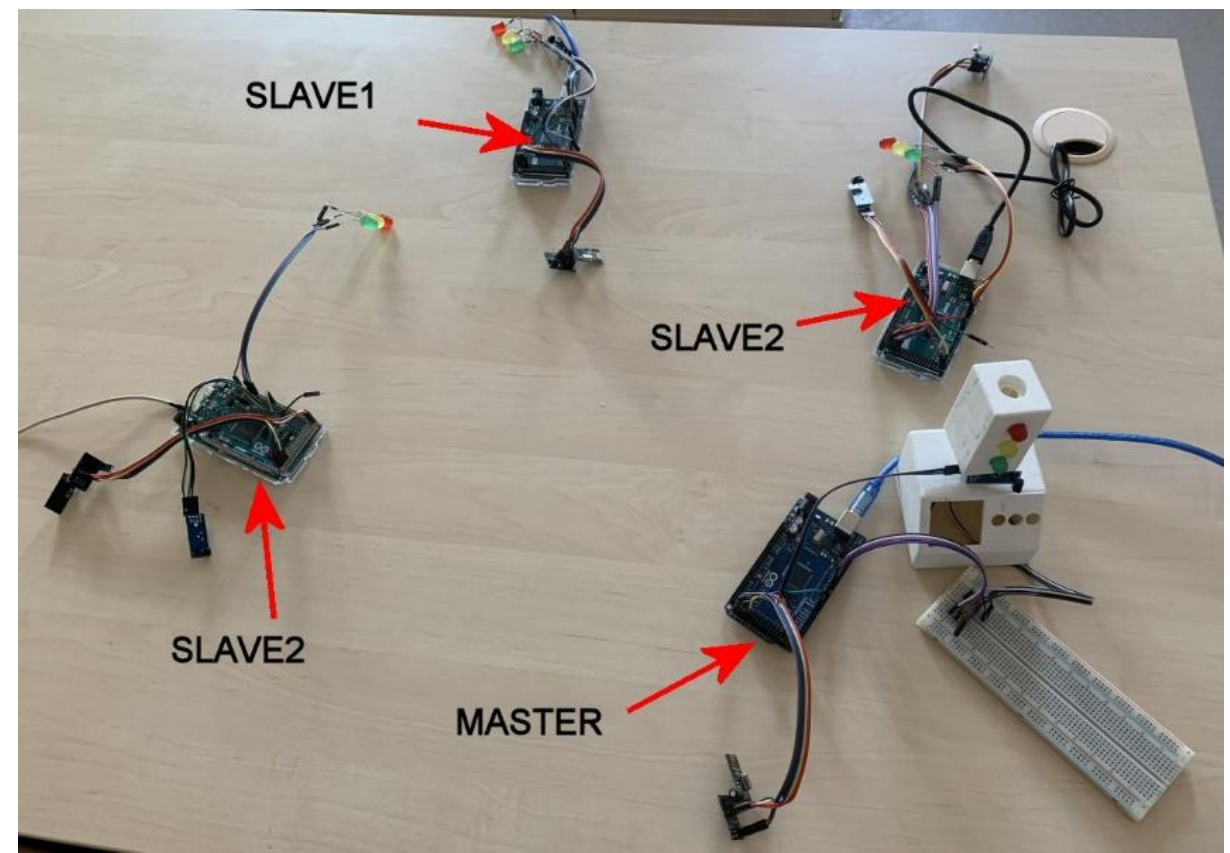

Fig. 4. Four control units

Four strategies are designed:

- Strategy 1 - Traffic lights are alternating with predefined time sequence only. (30s for green colour)

- Strategy 2 - Sensors of cars added. Arriving car changes these 30s to 10s and gets green sooner.

- Strategy 3 - One direction is the main and has green. Second direction has sensor of arriving car. When car arrives it gets green and after a while (30s) the green returns to main direction.

- Strategy 4 - Both direction have the same priority. Green is taken by sensors of arriving cars in both directions. 


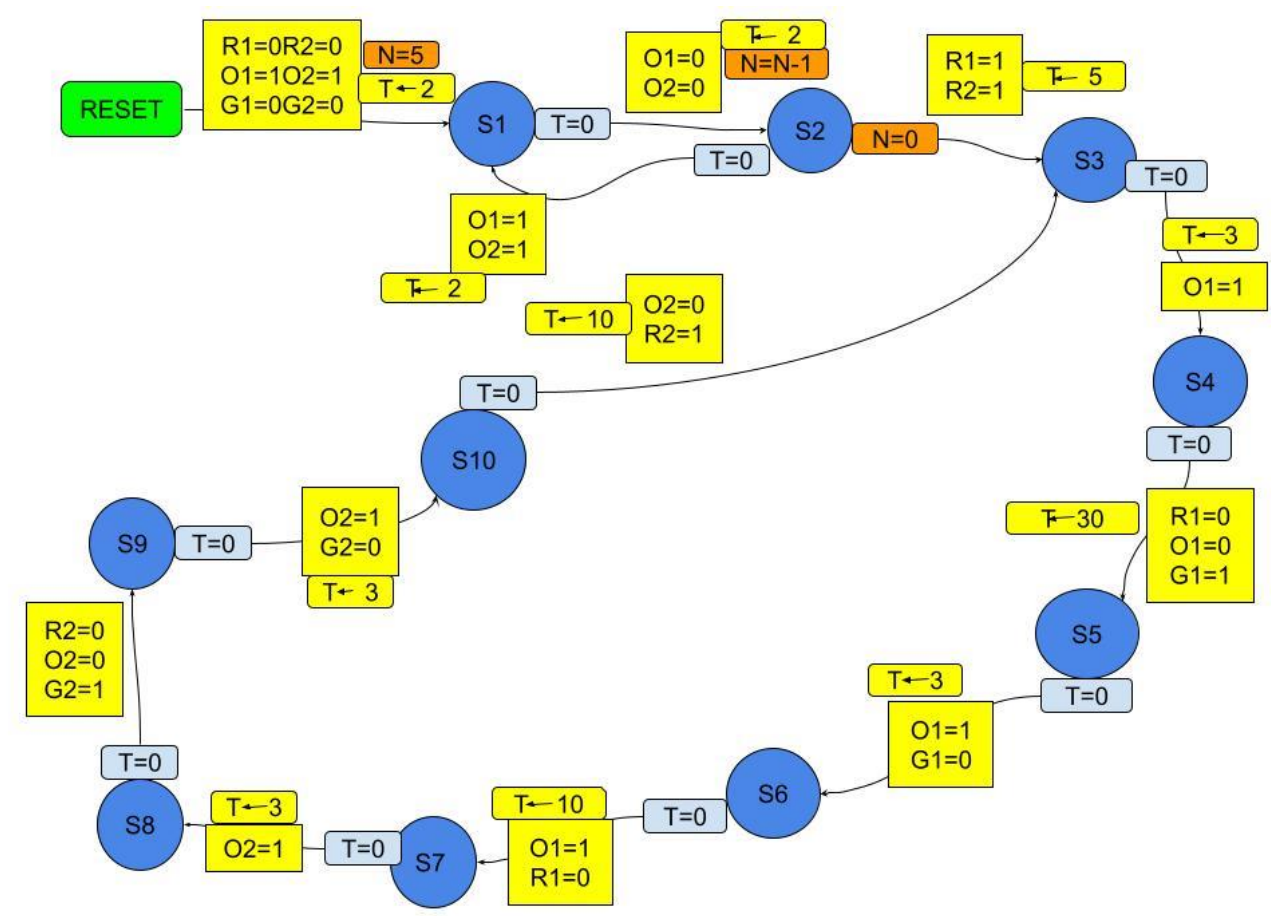

Fig. 5. The automaton of strategy $1-$ central control

The control algorithm is based on the automaton graph, Fig.5. The automatons and their components are described in the article [10]. In the Fig.5 there is a strategy 1 automaton for central control unit. It is necessary to split this automaton to three new automata for Master, Slave1 and Slave2 control units of the final solution with four masts. These automatons are in Fig.6, 7. And 8.

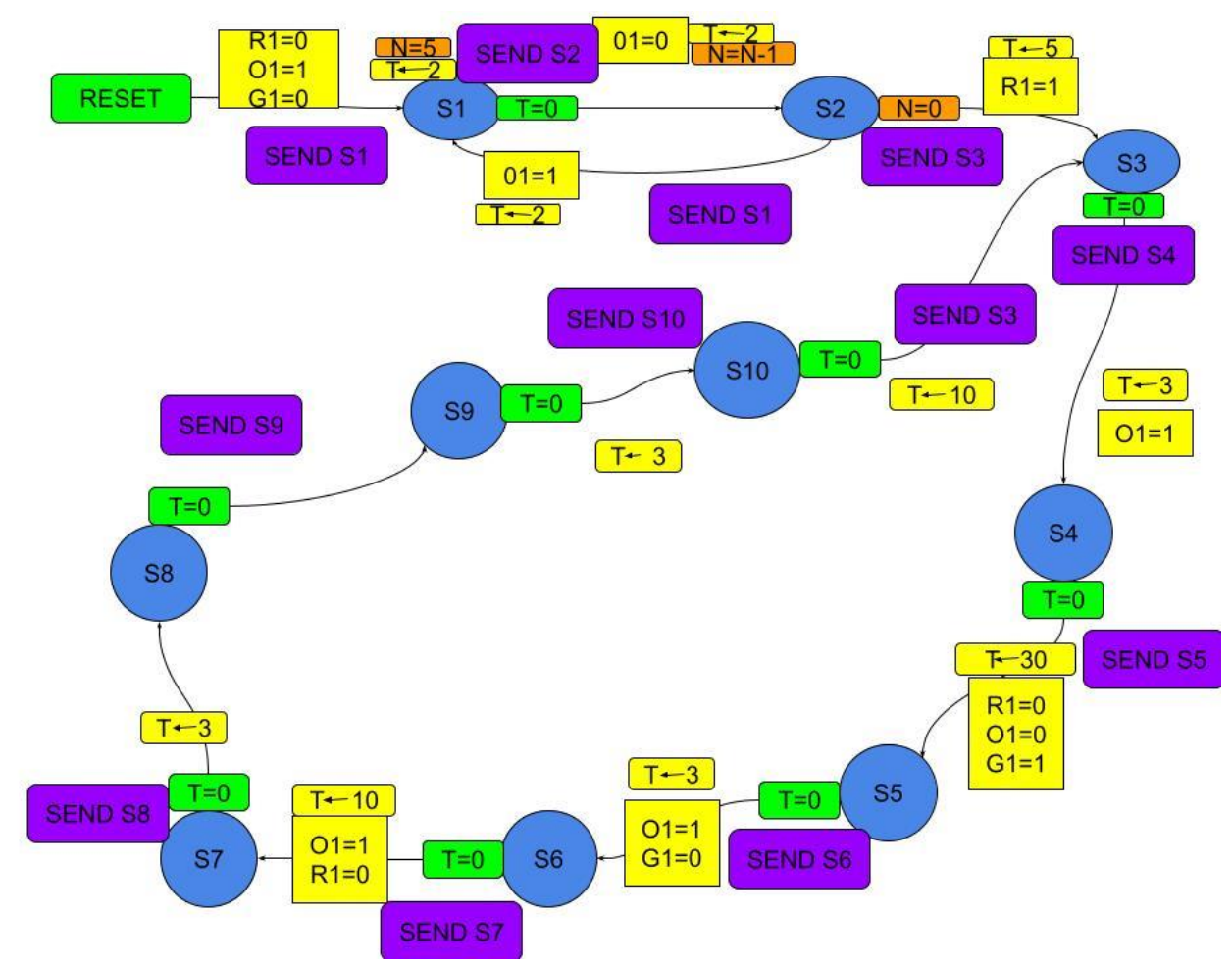

Fig. 6. The automaton of strategy $1-$ Master unit

The automaton for Master, Fig.6. is created by modifying the automaton in Fig.5. All action interventions with lights with index 2 are removed and the transmission of a synchronization signal with the current position in the automaton graph is added. The automations of Slave units receive this signals and changes their current position. 


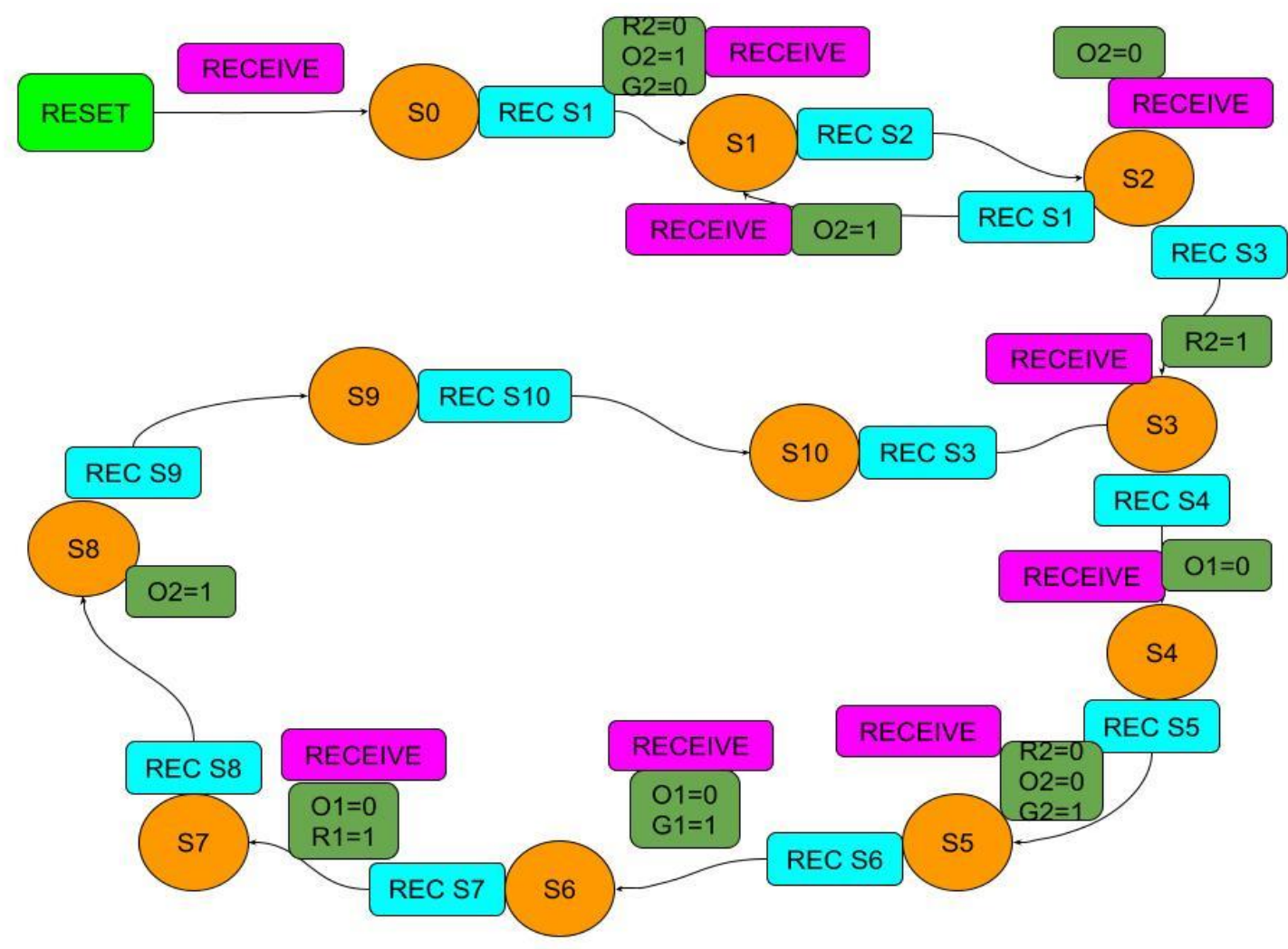

Fig. 7. The automaton of strategy $1-$ Slave1 unit

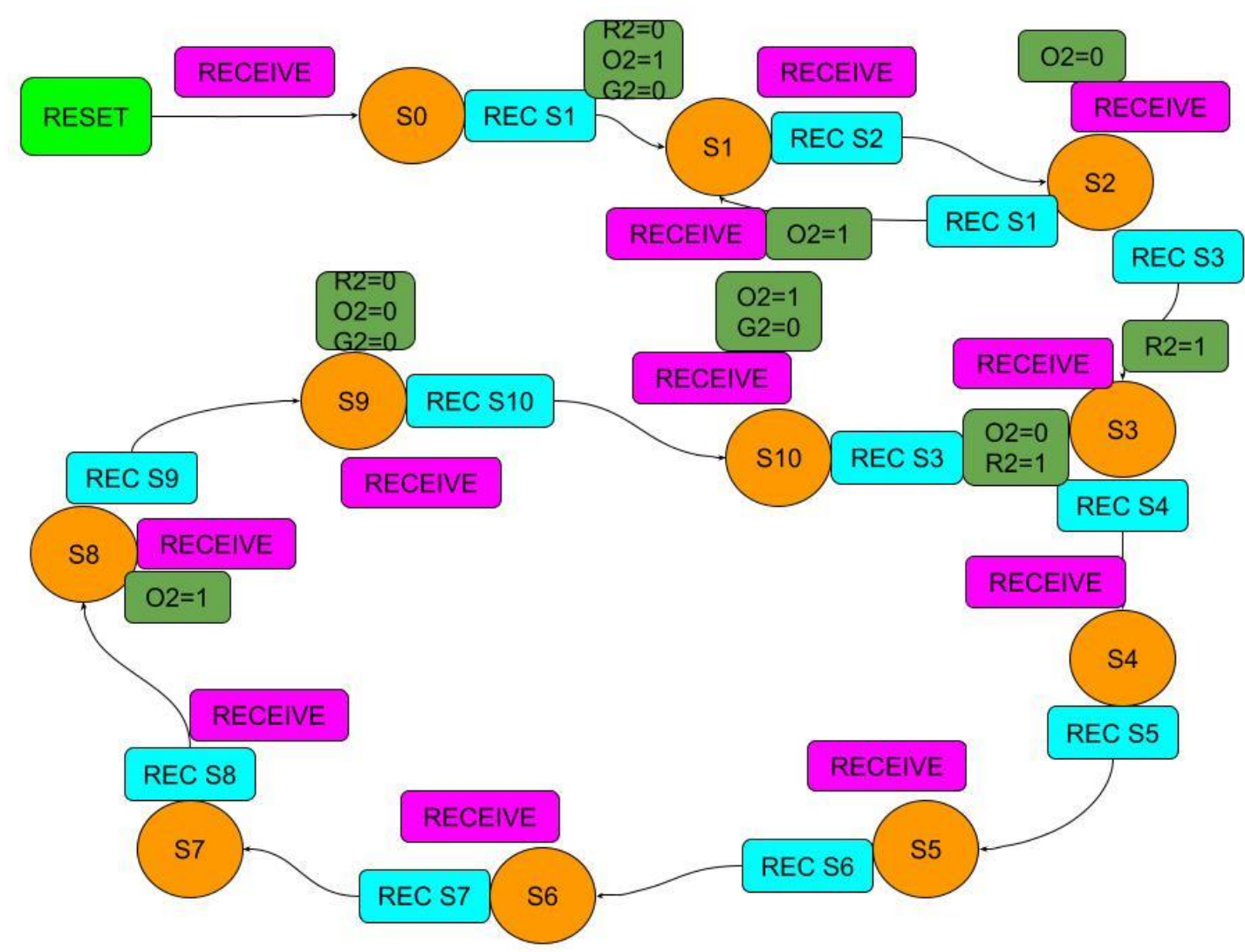

Fig. 8. The automaton of strategy $1-$ Slave2 unit 


\section{Conclusion}

The teaching model of the crossroad with traffic lights controlled by one central Arduino or four independent Arduinos was created. This control system is suitable for industrial using at real crossroad. The led diodes on the model are replaced with amplifiers and bigger LED lights. This was tested on real traffic lights. Several strategies were designed. First strategy was timing of lights only, when each direction has green for adjusted time. This strategy was improved using sensors of the car. In this case arriving car can decrease the time to green light - strategy 2. Next two strategies replace adjusted time to green forever of till the car in red direction appears. In this moment it takes green for itself and in strategy 3 it returns to previous direction after adjusted time or in strategy 4 the green stays forever or to next car at this road.

There were two control systems designed and created. One system is one Arduino which controls all lights, all four masts. It is not usable in real situation. Then the second control system was developed with four independent arduinos communication via wifi messages. The education model was created when one sample of the mast was printed on 3D printer. The next steps will be to improve the algorithms with regard to transmission security and to create a cover for the control unit.

\section{Acknowledgments}

This publication was written at the Technical University of Liberec as part of the project "(21278) - Optimization of manufacturing systems, 3D technologies and automation“" with the support of the Specific University Research Grant, as provided by the Ministry of Education, Youth and Sports of the Czech Republic in the year 2019.*

\section{References}

[1] Votrubec, R \& Koblasa, F. (2019). Control System of Vehicle for Smart Factory Model with Principles of Industry 4.0, Proceedings of the 30th DAAAM International Symposium, pp.0261-0267, B. Katalinic (Ed.), Published by DAAAM International, ISBN 978-3-902734-22-8, ISSN 1726-9679, Vienna, Austria

[2] Sevic, M. (2017). Design of small CNC machine for the model of production system with principles Industry 4.0. Master Thesis, Department of production systems and automation, Technical University of Liberec, Liberec, Czech Republic.

[3] Koblasa, F.; Votrubec, R.; Lelek, L. \& Koudelka, J. (2019). Project oriented teaching in Industry 4.0 - smart home. Industry engineering 2019: International student scientific conference. Pilsen, Czech Republic. ISBN 9788026108948.

[4] Bartodziej, Ch. J., (2016), The concept industry 4.0. New York, NY: Springer Berlin Heidelberg, ISBN 978-3-658165017.

[5] Thanes, L. \& Schaefer, D. (2017). Cybersecurity for Industry 4.0: Analysis for Design and Manufacturing. Switzerland: Springer International Publishing, ISBN 978-3-319-50659-3.

[6] Takakuwa, S.; Veza, I. \& Celar, S. (2018). Industry 4.0 in Europe and East Asia, Proceedings of the 29th DAAAM International Symposium, B. Katalinic (Ed.), Published by DAAAM International, ISBN 978-3-902734-20-4, ISSN 1726-9679, Vienna, Austria.

[7] Palcic, I.; Ojstersek, R. \& Buchmeister, B. (2018). Creating Value in Manufacturing Companies, Proceedings of the 29th DAAAM International Symposium, B. Katalinic (Ed.), Published by DAAAM International, ISBN 978-3902734-20-4, ISSN 1726-9679, Vienna, Austria.

[8] Medojevic, M.; Diaz Villar, P.; Cosic, I.; Rikalovic A.; Sremcev, N. \& Lazarevic, M. (2018). Energy Management in Industry 4.0 Ecosystem: a Review on Possibilities and Concerns, Proceedings of the 29th DAAAM International Symposium, B. Katalinic (Ed.), Published by DAAAM International, ISBN 978-3-902734-20-4, ISSN 1726-9679, Vienna, Austria.

[9] Ojstersek, R.; Acko, B. \& Buchmeister, B. (2020). Simulation study of a flexible manufacturing system regarding sustainability, International Journal of Simulation Modelling, Vol. 19, No. 1, 65-76, doi:10.2507/IJSIMM19-1-502

[10] Votrubec, R. (2020). Communication Layer between Control Units within the Internet of Things, Proceedings of the 31st DAAAM International Symposium, pp.0072-0079, B. Katalinic (Ed.), Published by DAAAM International, ISBN 978-3-902734-29-7, ISSN 1726-9679, Vienna, Austria, DOI: 10.2507/31st.daaam.proceedings.010 